\title{
Measuring the Antioxidant Capacity Induced by Reduced Thiols in Human Erythrocytes Using SW-Voltammetry
}

\author{
Maria Inês Mariano Vilhena, Marcos Vergílio Corrêa-da-Silva, Ana Carolina de Arruda, \\ Beatriz.Felício Ribeiro, Ana Laura Remédio Zeni Beretta and Armindo Antonio Alves* \\ Graduate Program in Biomedical Sciences, Herminio Ometto University Center - UNIARARAS, \\ Araras-SP Brazil. \\ *E-mail: alvesaa@uol.com.br
}

doi: $10.20964 / 2016.08 .52$

Received: 7 April 2016 / Accepted: 11 June 2016 / Published: 7 July 2016

This study examines the use of square wave voltammetry (SWV) to measure the antioxidant capacity induced by reduced thiols in human erythrocytes using a static mercury drop (working), a platinum wire (auxiliary) and the $\mathrm{Ag} / \mathrm{AgCl}$ saturated electrode. The erythrocytes were isolated from fresh collected blood of 15 subjects aged between 20-30 years old. The applayed voltage ranged from - 0.8 to $-0.4 \mathrm{~V}$. The current intensity peak (Ip) increases with the hemoglobin concentration $(11.3-86.0$ $\mu \mathrm{mol} / \mathrm{L}$ ) of the erythrocyte mixture (line equation $\mathrm{R}=0.9$ ), increasing additions of reduced glutathione $(0-90 \mu \mathrm{mol} / \mathrm{L})$ to $23 \mu \mathrm{mol} / \mathrm{L}$ of hemoglobin. The signal decreases when increasing concentrations of diamide (a specific thiol ligant) $(0-46 \mathrm{mmol} / \mathrm{L})$ was added to the erythrocyte preparation $(70.0$ $\mu \mathrm{mol} / \mathrm{L}$ hemoglobin). This decreasing was fitted by a quadratic equation $\left(\mathrm{R}^{2}=0.99\right)$. The $\mathrm{SWV}$ method demonstrate to be more adequate to quantify the oxidative attack promoted by small concentrations of $\mathrm{H}_{2} \mathrm{O}_{2}(0-53 \mu \mathrm{mol} / \mathrm{L})$ to the erythrocyte preparation $(65 \mu \mathrm{mol} / \mathrm{L}$ hemoglobin), when compared to the spectrophotmoetric method that detect the diminishment of oxyhemoglobin and increase of methemoglobin and hemichrome. These results allow the use of the proposed method to quantify alterations in the antioxidant status of the human erythrocytes.

Keywords: SW voltammetry, erythrocyte oxiadtive status, reduced thiols.

\section{FULLTEXT}

(C) 2016 The Authors. Published by ESG (www.electrochemsci.org). This article is an open access article distributed under the terms and conditions of the Creative Commons Attribution license (http://creativecommons.org/licenses/by/4.0/). 